\title{
The Acoustics of Politics and its Influence on Urban Soundscapes
}

\author{
El-moutasam Aziz \\ The International University of Beirut \\ Michel Abi Chahla street, Mousytbeh \\ Beirut-Lebanon \\ elmoutasam.aziz@b-iu.edu.lb
}

\author{
Laila Manasfi \\ The International University of Beirut \\ Michel Abi Chahla street, Mousytbeh \\ Beirut-Lebanon \\ laila.manasfi@b-iu.edu.lb
}

\begin{abstract}
Beirut's mid-century soundscape was a vibrant one, yet by 1975 the Lebanese civil war denigrated this vibrancy into chaos. A soundscape once resonating with the echoes of biological, natural, and human sounds has been denigrated by decades-long political strife resulting in a drowning-out of biophonic and geophonic sounds in a present day soundscape dominated by anthrophonic noises. This paper is part of an ongoing research endeavor which seeks to examine the acoustic effects of political strife on urban soundscapes. Data collection, evaluation and analysis will be compared in an effort to ascertain the impact of years of political strife on urban centers.
\end{abstract}

Keywords: Urban soundscape. Soundscape ecology. Biophony. Geophony. Anthropophony. Memory

\section{INTRODUCTION}

Beirut's mid-century soundscape was a vibrant one, yet by 1975 the Lebanese civil war denigrated this vibrancy into total chaos. A soundscape once resonating with the echoes of biological (i.e., biophony), natural (i.e., geophony), and human (anthropophony) sounds has been denigrated by decades-long political strife resulting in a drowning out of biophonic and geophonic sounds resulting in a present day soundscape dominated by anthrophonic noises!

Comprehensive soundscape (i.e., biophony, geophony, and anthropophony) data will be obtained through semi-structured interviews with lifelong residents of the city, audio and video archives, and field acoustic recordings to answer the research question driving the study; "How does political strife influence the soundscape of urban settings?" Specifically, we aim to utilize theoretical data to reconstruct Beirut's pre-political strife "Mnemosynephony" (i.e., memory-based) soundscape which will then be compared to its' current ecological soundscape in an effort to ascertain the impact of years of political strife on such a soundscape.
The findings of this study will provide a framework which we term (Mnemosynephony) for gauging the impact and effect of war and political strife on the ecological soundscape of urban centers and pave the way or further research in the field of soundscape ecology.

\section{A GOLDEN AGE LONG GONE}

The onset of Lebanon's Golden Years came about in the mid-1950's. A soundscape once resonating with biophonic (i.e., biological), geophonic (i.e., natural), and anthropophonic (i.e., human) generated sounds, is now chaotically dominated by the latter. This chaos continues to present day, perpetuated by intermittent war and political strife.

The Lebanese capital city of Beirut, was regarded as a boisterous cosmopolitan city where life was prosperous, glamorous and bustling with tourism. The intensity of its western and eastern influences synthesized a unique fusion of east and west which caused a striking attraction for many. It was a welcoming and tolerant sanctuary and a cultural crossroads serving as a gateway between east and west. During this time, Beirut, was awarded surrogate names such as "The Paris of the Orient","The Jewel of the Levant", and "The Switzerland of the Middle East". 
Between 1950 and 1975 Beirut became a major regional hub for fashion and art attracting many luxury and glamour seekers. Eventually, some of the most Revered poets in the Arab world such as Nizzar Qabbani would write to Beirut. Some of Qabbani's writing includes, To Beirut the Feminine, With My Love, and Lady of universe Beirut. Mahmoud Darwish also wrote Qasidat Bayrut (Ode to Beirut) which has been adopted by Lebanese singing artists such as Marcel Khalife and Majida Al Roumy, all of which has reflected the importance of this cultural landmark and pinning it as a critical point in civilization. Beirut was the land of roses, milk and honey, the land of the cedars and lemon blossoms which filled the streets and drenched the air. Beirut was considered a city of bliss and a trilingual cultural attraction sealing the gap between east and west. Beirut was also synonymous with French culture, as the French colonization of Lebanon gave the city's urban planning and social customs distinguishing features. Furthermore, it was famous for its coffee shops, shopping centers, horse racing, hotels, beaches, and cinemas. Nature was likewise very well maintained and very well regarded, moreover life in Beirut was roaring with stylish fancy living and prosperity for all.

The 1970s and ensuing decades witnessed a disintegration of Beirut's Golden Years, transitioning the city into a period considered the darkest era of Lebanon's history. A 15 yearlong barbaric civil war had thrown the country into chaos and the subsequent political/sectarian strife transformed the city's landscape from one characterized with vibrant biophonic sounds (i.e. biological) such as the chorus of birds calling to each other, geophonic (i.e., natural) sounds such as that of ocean waves crashing on its shores, and anthropophonic (i.e., human) such as people enjoying their everyday activities, to one dominated by the latter's noise. This transformation gave birth to an urban soundscape rife with the keynotes of a human activity such as Israeli warplanes breaking the sound barrier, roof tops humming with the sounds of diesel generators, streets echoing with the sounds of congested streets, and an urban landscape suffocated by building and structures.

\section{A SHIFTING SOUNDSCAPE}

The decades long Lebanese civil war not only changed the landscape by causing a demarcation of Beirut into sectarian partitions, nevertheless, the soundscape saw a major shift as well. Today's keynote city sounds (e.g., Backup generator engines, military helicopters, aggressive street vendors) have become a constant representational reminder of the harsh memory of the sound of war, the memory of gunfire, missiles and explosions. This new soundscape is visually reinforced by bullet riddled residential buildings still standing amid today's modernization as a sustainable reminder of the past. One Beirut resident says "We are a loud people because of a culture that was shaped by war". When kids' voices are heard on the street playing, it's because of political/governmental reasons that they don't have a specific space to play in. Street vendors in their many forms sell anything from Lebanese street cakes to used spare parts implies socio/economic and political issues which can be equally linked to the refugee crisis, a problem that has been exacerbating since the war in neighboring Syria began in 2011. Many street vendors are refugees that cannot access decent work and so they resort into being travelling vendors and inevitably evolving to become pure indicators of displacement.

The sounds of the environment are so loud that many residents claim to have gotten accustomed to them to the point that they do not hear anything or anyone because there is an oversaturation of sounds consuming the city day and night. "It's as if the sounds are at a high frequency that we are unable to hear them with our human ears" states another resident of the city. A third resident claims, "Peoples voices become louder and louder to be heard on top of the sound of the environment which eventually becomes a sound perceived as a second nature, blended unto people's lives". This is similar to the nightingales (Pijanowski, 2011).

It seems that soundscapes don't exist anymore or rather people don't hear them to any further extent, what they hear is the urban sounds of the manmade machines and voice interactions. The Palestinian, Syrian, Iraqi, Libyan and other refugees that fled to Lebanon can still hear the sound of war through the urban environment. The cities daily activity is a representation of war at a lower frequency/intensity however a war nonetheless. Although people are visually living a normal day's event, the sound representation is incompatible and does not reflect the image. People get by with their lives while living in a perpetual auditory war resulting from the loud sounds of machines that emanate similar sounds of war machines. We have introduced a new term 
Mechaphony to describe sounds emanating from the machines. People flee wars only to come live in a country that is the representation of war itself, perhaps a dark irony to Beirut's soundscape. Another issue is that the keynote sounds which emerged from political strife have seeped from exteriors into people's homes, case in point, due to frequent power outages; most residents will utilize an uninterruptible power supply (UPS) in their homes and offices, to provide emergency power to personal computers. During the onset of a power outage, new keynotes emerge since UPS's will continuously beep and will slowly increase as the battery wears down until power is restored. Currently, few studies have examined these types of sound representations/associations in relevance to political strife which this study aims to address.

\section{RECONSTRUCTING THE PAST}

The significance of this research is that it provides a framework to reconstruct sounds from the past to compare to the present providing the ability to assess the impact of war and political strife on urban soundscapes. One way to better understand the present and future soundscape of an urban setting is by examining, assessing and evaluating its past. The past shapes the future and it is fundamental to identify with soundscape ecology, and specifically one that is related to memory based ecological soundscapes (Mnemosynephony) which produce audible representations and associations that affect the sociopolitical and the environmental psychology of the city. As we write this section of the paper, we cannot help but pointing out the military-grade-helicopter which is hovering over our residential building at $8: 48 \mathrm{pm}$. It seems a constant reminder of the past is always present.

\section{MNEMOSYNEPHONY [NEE-MOS-UH-NEE- FOH-NEE]}

The purpose of this study is to examine the effects of political strife on urban soundscapes. Specifically, it will examine the acoustic effects of the Lebanese civil war on Beirut's soundscape through the lens of soundscape ecology (Pijanowski, 2011) and will provide a new framework (Mnemosynephony) for the advancement of soundscape ecological studies. Mnemosynephony presents memory-based ecological soundscapes and their link to historical memory either by sound representations, associations, or personal experience. This study also aims to reveal how memory based ecological soundscapes emerging from the trauma of war affects societal wellbeing.

\section{SOUNDSCAPE ECOLOGY}

Many research is being carried out in various areas of acoustic studies and according to Schafer (Schafer, 1994, p. 3), the research being carried out is in some way or another asking the same question, "what is the relationship between man and the sounds of his environment and what happens when those sounds change?"

The soundscape can be defined as "the collection of biological, geophysical and anthropogenic sounds that emanate from a landscape and which vary over space and time reflecting important ecosystem processes and human activities" (Pijanowski, 2011).

As urbanization manifests itself in the modern era, both biophonic (i.e., animal) and geophonic (i.e., nature) sounds take a backseat to anthropogenic (i.e., human) produced sounds.

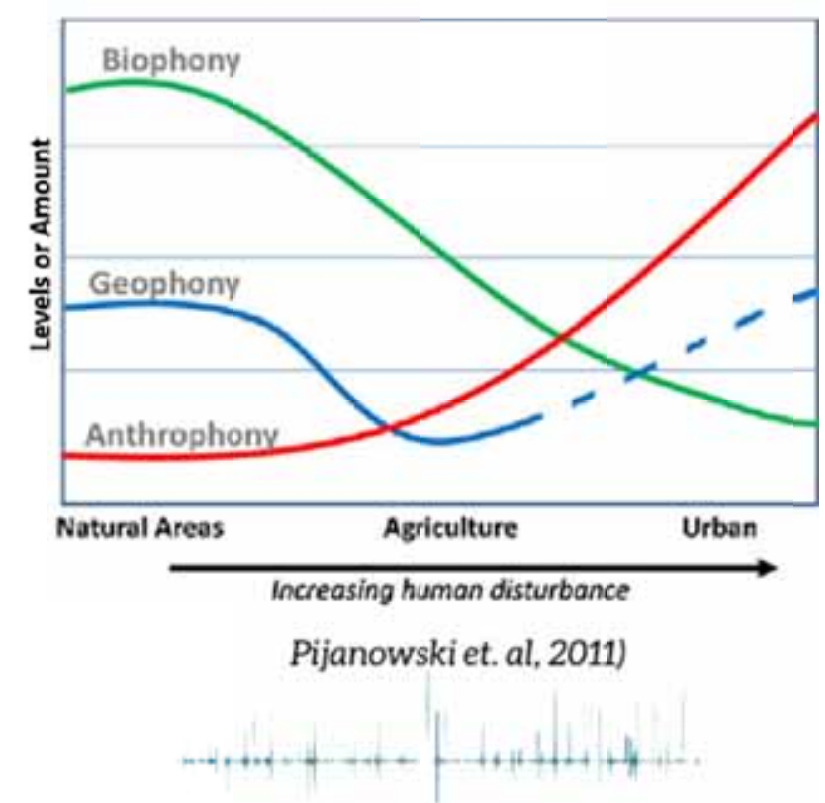

And although this is predominating urban soundscapes across the globe, Lebanon's decade's long political strife is exacerbating the issue. To further define each of the three elements, (Pijanowski, 2011) defines biophony as a collection of sounds produced by all organisms at a location over a specified time. Geophony is defined as 
sounds originating from the geophysical environment, which included wind, rain, thunder and movement of the earth, ... etc., and anthropophony as sounds produced by stationary (e.g., air conditioning units) and moving (e.g., vehicles) human made objects.

Many studies examined this phenomenon from differing angles. Yet no one study has examined this issue from a socio-political angle which this study aims to do. Many theories and ideas have been written about environmental sounds and soundscape ecology. Rehan (2014) examined how environmental sounds can be used as a resource in urban space development, like many he also examined noise abatement and legislation, sonic diversity and acoustic ecology, and the phonic identity of a city. Muller (2012), examined sustainability of soundscapes and noise policy, acoustic memory, psychoacoustics, noise management strategies, soundscape and identity, and environmental noise policy. Revill (2000), assessed cultural politics of sound, how music gives a form of cultural authority, as well as how sound arrangement fashions societies. However, no studies to the best of our knowledge address how politics may influence the soundscape of a city.

\section{RECONSTRUCTING THE PAST THROUGH THE PRESENT}

How do urban soundscapes change after the advent of political strife?

To attempt to answer this question, different variables will need to be examined closely; this analysis will utilize a phenomenological qualitative research focusing on an urban soundscape (in this case Beirut). The participants of this research need be longtime residents of the city, and data collection will be conducted in three stages, stage one consists of semi-structured interviews, the second stage consisting of bio, geo, anthro, -phonic recordings and the final stage is by searching for and collecting archival records. Data analysis will be carried out through interview recordings supported by verbatim transcriptions, inductive analysis of the interview data, and by seeking major themes across interviews. A comparative analysis of pre and post political strife city soundscape will juxtapose the current (post-political strife) soundscape with the past (pre-political strife) soundscape. A side by side comparison between interviews with longtime residents of Beirut will be conducted to gather their perspective on the postpolitical strife soundscape of the city in comparison to interviews with longtime residents of Beirut to gather their perspective on the pre-political strife soundscape of the city. Furthermore, audio/video recordings of Beirut's current soundscape will be compared to audio/video archival records of Beirut's past soundscape. Doing so will reveal how political strife has caused an increase in anthropophonic sounds (e.g., unreliable electrical grid) that lead to the use of portable generators which drown out biophonic sounds.
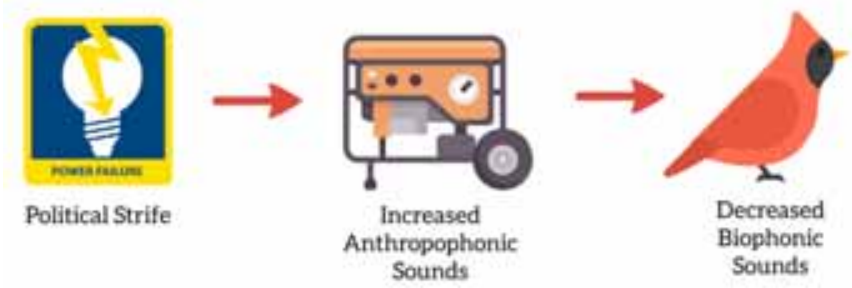

Another example would be how armed conflict leads to the use of military helicopters which drown out geophonic sounds, political strife increases anthropophonic sounds and ultimately decreases geophonic sounds.
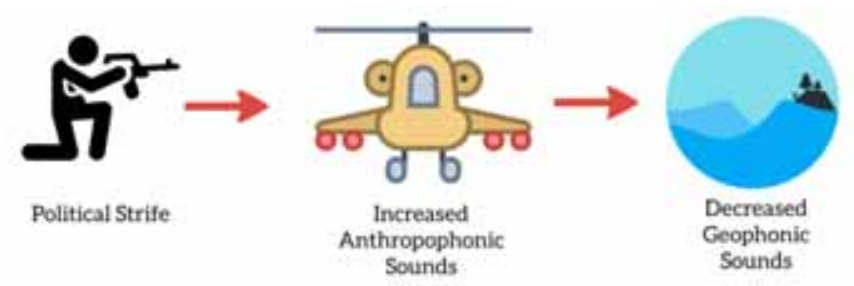

Emerging themes based on the pre/post political strife biophony, geophony and anthropophony themes will be used as the premise for creating Mnemosynephony (i.e., memory-based) ecological soundscape which will then be compared to its current ecological soundscapes in an effort to ascertain the impact of years of political strife on such a soundscape. This new framework (Mnemosynephony) will be utilized to reconstruct pre-strife Beirut soundscape by using interview data to detail how it would have sounded like and using current sounds to reconstruct this in audio format. A construction of what post-strife Beirut soundscape of the city will be made through the use of current city sounds and comparing the past to the current to highlight the effect of political strife on the city's soundscape. This analytical research process will be the protocol used on a global scale to test our prediction and hypothesis that political strife does change urban soundscapes. 


\section{REFERENCES}

Pijanowski, B. C., Villanueva-Rivera, L. J., Dumyahn, S. L., Farina, A., Krause, B. L., Napoletano, B. M., ... \& Pieretti, N. (2011). Soundscape ecology: the science of sound in the landscape. BioScience, 61(3), 203-216.

Schafer, R. M. (1993). The soundscape: Our sonic environment and the tuning of the world. Simon and Schuster.

Rehan, R. M. (2016). The phonic identity of the city urban soundscape for sustainable spaces. Hbrc Journal, 12(3), 337-349.

Müller, J. (2012). Music and the politics of sound: nationalism, citizenship,

and auditory space acoustic memory: Where psychology and history converge. Culture \& Psychology, 18(4), 443-464.

Revill, G. (2000). Music and the politics of sound: nationalism, citizenship, and auditory space. Environment and Planning D: Society and Space, 18(5), 597-613.

Attali, J. (1985). Noise: The political economy of music. Minneapolis: University of Minnesota Press.

Chion, Michel, 1947-. (1994). Audio-vision : sound on screen. New York :Columbia University Press.

Freud, S., McLintock, D., \& Haughton, H. (2003). The uncanny. New York: Penguin Books.

Feld, S., \& Brenneis, D. (2004). Doing anthropology in sound. American Ethnologist, 31(4), 461-474.
Burkhalter, T. (2007). Mapping Out the Sound Memory of Beirut: A survey of the music of a war generation. Itinéraires esthétiques et scènes culturelles au Proche-Orient, 103-125.

Cox, C. (2011). Beyond representation and signification: Toward a sonic materialism. Journal of visual culture, 10(2), 145161.

Simpson, P. (2017). Sonic affects and the production of space:'Music by handle'and the politics of street music in Victorian London. cultural geographies, 24(1), 89-109.

Garrioch, D. (2003). Sounds of the city: the soundscape of early modern European towns. Urban History, 30(1), 5-25.

Adams, M., Cox, T., Moore, G., Croxford, B., Refaee, M., \& Sharples, S. (2006). Sustainable soundscapes: Noise policy and the urban experience. Urban Studies, 43(13), 2385-2398.

Wrightson, K. (2000). An introduction to acoustic ecology. Soundscape: The journal of acoustic ecology, 1(1), 10-13.

Zhang, M., \& Kang, J. (2007). Towards the evaluation, description, and creation of soundscapes in urban open spaces. Environment and Planning B: Planning and design, 34(1), 68-86. 